\title{
Facial dysmorphism: a marker of autosomal dominant cranial diabetes insipidus
}

\author{
R B S Laing, J C S Dean, D W M Pearson, A W Johnston
}

\begin{abstract}
We report a family with autosomal dominant cranial diabetes insipidus in which a characteristic facial appearance of hypertelorism, broad and prominent nasal bridge, short nose, and long philtrum is seen in affected members.
\end{abstract}

Familial cranial diabetes insipidus in man is inherited as either an autosomal dominant ${ }^{1}$ or an $\mathrm{X}$ linked recessive trait. ${ }^{2}$ In the rat, an autosomal recessive form of cranial diabetes insipidus is associated with a mutation in the gene encoding vasopressin. We report a family with autosomal dominant cranial diabetes insipidus in which a characteristic midline facial dysmorphism was found in affected subjects. This finding, which has not been recorded previously, is consistent with an embryonic or developmental origin of the endocrine dysfunction.

\section{Case reports}

CASE 1

Case $1(\mathrm{IV} \cdot 5)$ presented at the age of 13 with a lifelong history of thirst, polydipsia, and polyuria. There was a family history of diabetes insipidus (fig 1). On examination he was $175.9 \mathrm{~cm}$ tall (above the 97th centile); visual field testing and olfactory assessment proved normal and sexual development was at pubertal stage V. Ocular hypertelorism, epicanthic folds, and a broad, prominent nasal bridge with relatively short nose and long philtrum were noted (fig 2, table 1) and his mother commented that other affected family members had a similar facial appearance. CT head scan showed no abnormality

Department of Clinical Genetics, Ward 3, Aberdeen Royal Infirmary, Aberdeen AB9 2ZB.

J C S Dean, A W Johnston

Department of Diabetes and Endocrinology, Ward 3, Aberdeen Royal Infirmary, Aberdeen AB9 2ZB.

R B S Laing, D W M Pearson

Correspondence to Dr Laing.

Received for publication 10 July 1990.

Revised version accepted for publication 2 January 1991.

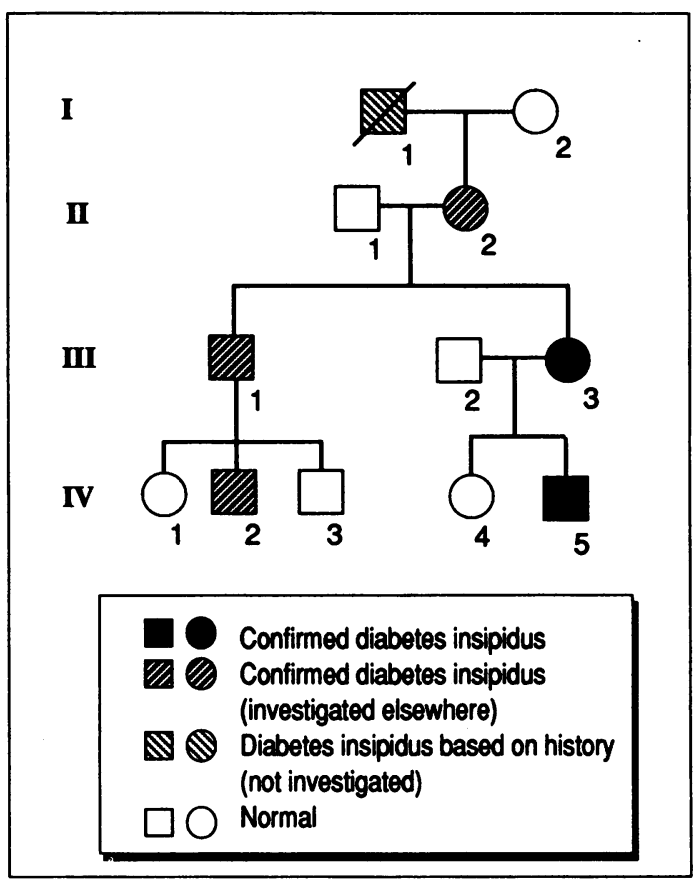

Figure 1 Family pedigree.

and a water deprivation test with DDAVP (1-deamino8-D-arginine vasopressin) challenge was consistent with cranial diabetes insipidus (table 2A).

\section{CASE 2}

Case 2 (III $\cdot 3$ ), a 38 year old woman, presented after her son had been diagnosed as having diabetes insipidus. She gave a history of polydipsia, polyuria, and nocturia which began in her teens. She had breast fed both her children. Physical examination, including visual field and olfactory assessment, was normal and, apart from the absence of epicanthic folds, a similar dysmorphism was evident (fig 3, table 1). The biochemical results during water deprivation with DDAVP challenge (table 2B) were consistent with cranial diabetes insipidus. 

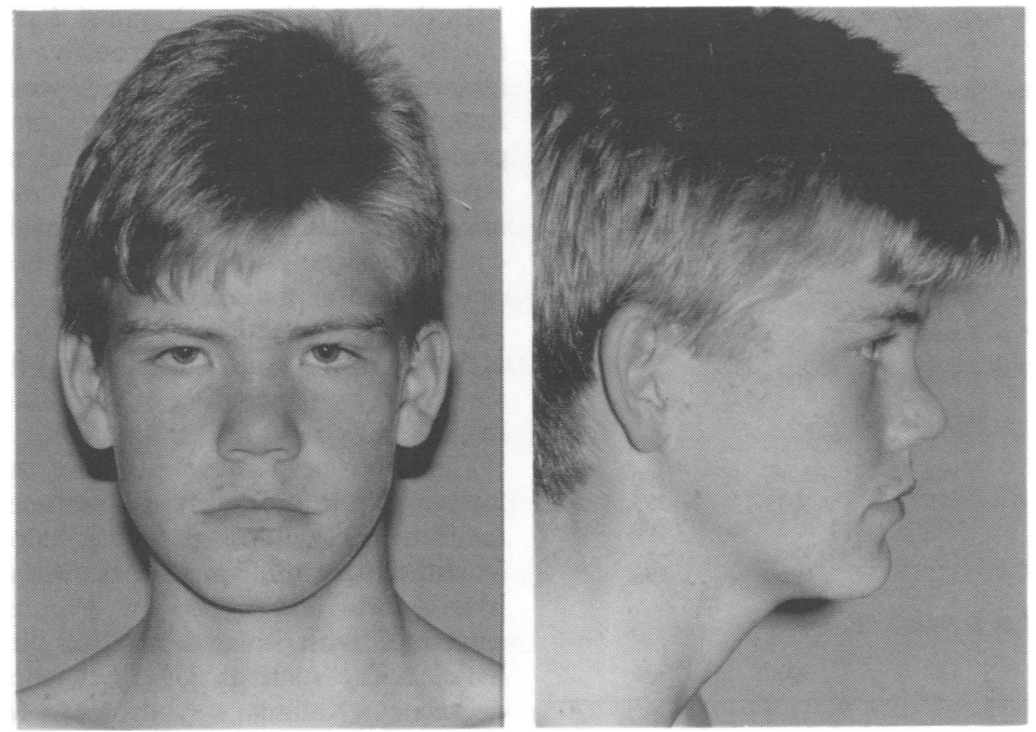

Figure 2 Anterior and lateral facial views of case $1(I V \cdot 5)$. Note epicanthus, ocular hypertelorism, broad nasal bridge, short nose, and long philtrum.

Table 1 Measurements of inner canthal distance (ICD) and occipitofrontal circumference $(O F C)$ in two dysmorphic and two normal family members.

\begin{tabular}{lll}
\hline Family member & \multicolumn{1}{c}{ ICD $(\mathrm{cm})$} & \multicolumn{1}{c}{ OFC $(\mathrm{cm})$} \\
\hline IV·5 (case 1) & $3.5(+2 \mathrm{SD})$ & $56(90$ th centile) \\
IV·4 & $3.0(-0.5 \mathrm{SD})$ & 56.5 (97th centile) \\
III.3 (case 2) & 3.4 (+1 SD) & 54.5 (50th centile) \\
III.2 & 3.2 (mean) & 58.0 (>97th centile) \\
\hline
\end{tabular}

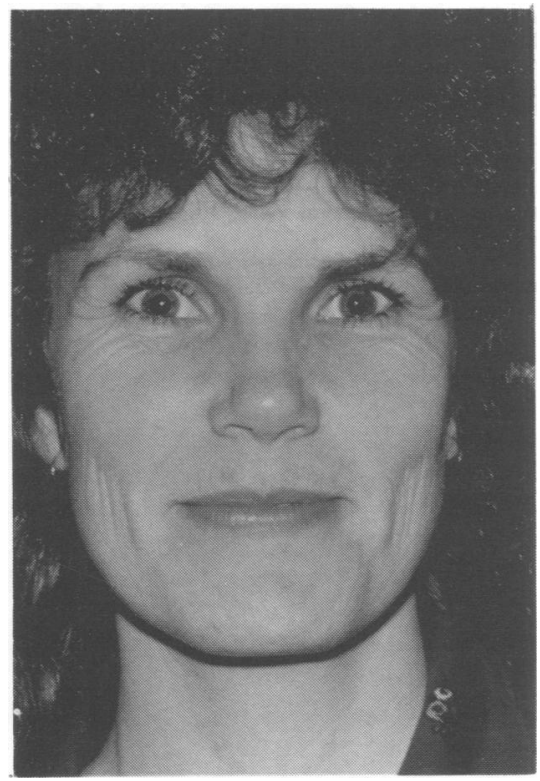

Figure 3 Facial appearance of case $2(I I I \cdot 3)$ showing hypertelorism, broad nasal bridge, short nose, and long philtrum.

\section{Family history}

IV. 4 was investigated at the same time as her mother and found to have a normal response to water deprivation. She did not share the facial dysmorphism of her mother and brother (fig 4, table 1 ). II $\cdot 2$, III $\cdot 1$, and IV 2 were investigated elsewhere and confirmed to have cranial diabetes insipidus by water deprivation test. We are told that, unlike other family members,

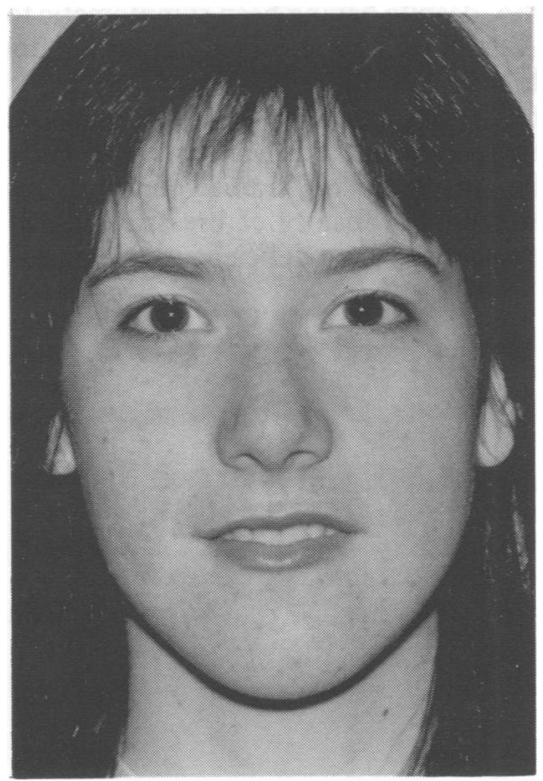

Figure 4 Facial appearance of IV 4 (normal). 
Table 2 Results of water deprivation test in cases 1 and 2.

\begin{tabular}{lcccc}
\hline $\begin{array}{l}\text { Time } \\
(\mathbf{h})\end{array}$ & $\begin{array}{c}\text { Weight } \\
(\mathbf{k g})\end{array}$ & $\begin{array}{c}\text { Urine } \\
\text { osmolality } \\
(\mathbf{m m o l} / \mathbf{k g})\end{array}$ & $\begin{array}{c}\text { Urine } \\
\text { volume } \\
(\mathbf{m l})\end{array}$ & $\begin{array}{c}\text { Serum } \\
\text { osmolality } \\
(\mathbf{m m o l} / \mathbf{k g})\end{array}$ \\
\hline A CASE 1 & & & & \\
0 & $56 \cdot 5$ & 189 & - & 286 \\
1 & $\overline{1}$ & 181 & 300 & 290 \\
4 & $55 \cdot 0$ & 126 & 800 & 292 \\
6 & $55 \cdot 0$ & - & 560 & - \\
7 & $54 \cdot 5$ & 218 & 760 & 294
\end{tabular}

Given $2 \mu \mathrm{g} D \mathrm{DAVP}$ at 8 hours

$\begin{array}{lrrrr}81 / 2 & 54 \cdot 5 & 666 & 200 & 287 \\ \text { B CASE 2 } & & & & \\ 0 & 57 \cdot 0 & 145 & -59 & 290 \\ 1 & \overline{56} \cdot 5 & 104 & 550 & 293 \\ 4 & 56 \cdot 0 & \overline{117} & 450 & \frac{300}{296} \\ 6 & 56.0 & 117 & 690 & \end{array}$

Given $2 \mu \mathrm{g} D D A V P$ at 8 hours

$81 / 2$

$56 \cdot 0$

187

300

306

the latter three patients share the dysmorphic features of cases 1 and 2 and this has been verified by review of family photographs.

\section{Discussion}

It is known that there is considerable interfamilial variation in the severity of autosomal dominant cranial diabetes insipidus, but there is also a tendency within families to regard the disease, even when severe, to be no more than an unpleasant family habit. ${ }^{3}$ This appears to have been the case for II $\cdot 2$ and III 3 who, despite having been symptomatic for many years, did not present to medical attention until their seventh and fourth decades respectively.

In the family reported here, there exists a definite correlation between the facial dysmorphism described and the presence of cranial diabetes insipidus. Furthermore, the history of breastfeeding in case 2 indicates that oxytocin deficiency is not a feature.
In the Brattleboro rat $^{3}$ cranial diabetes insipidus is inherited as an autosomal recessive trait in which an abnormal, inactive vasopressin is produced owing to a frameshift mutation in the gene encoding the vasopressin hormone precursor. ${ }^{4}$ In man, the usual familial form of the disease is dominantly inherited and it is difficult to envisage how an abnormal peptide could produce a dominantly inherited effect. A developmental anomaly, rather than an abnormal vasopressin molecule, would seem a more likely aetiology in the human disease and this hypothesis is supported by the finding of a midline facial anomaly in the family reported.

Global or near global pituitary deficiency is well known in the major cranial midline developmental malformation syndromes such as holoprosencephaly. ${ }^{5}$ In addition, midline anomalies such as olfactory lobe hypo/aplasia and hyper- or hypotelorism may be associated with isolated anterior pituitary hormone deficiencies, such as GH deficiency ${ }^{5}$ and LHRH deficiency (Kallman's syndrome). ${ }^{6}$ Midline developmental anomalies of the brain associated with cranial diabetes insipidus have been reported in isolated cases. ${ }^{7}$ This is the first report describing evidence of an inherited midline developmental anomaly (dysmorphic facial features) associated with cranial diabetes insipidus.

1 Pederson EB, Lamm LU, Albertson $\mathrm{K}$, et al. Familial cranial diabetes insipidus: a report of five families. Genetic, diagnostic and therapeutic aspects. $Q \mathcal{F}$ Med 1985;57:883-96.

2 Forssman $\mathrm{H}$. Two different mutations of the $\mathrm{X}$ chromosome causing diabetes insipidus. Am $\mathcal{F}$ Hum Genet 1955;7:21-7.

3 Rimoin DL. Genetic disorders of vasopressin deficiency. In: Emery AEH, Rimoin DL, eds. Principles and practice of medical genetics. Edinburgh: Churchill Livingstone, 1983:1145-7.

4 Ivell R, Schmale H, Krisch B, Nahke P, Richter D. Expression of a mutant vasopressin gene: differential polyadenylation and read-through of the mRNA $3^{\prime}$ end in a frame shift mutant. $E M B O \mathcal{F}$ 1986;5:971-7.

5 Rimoin DL, Schimke RN. Genetic disorders of the endocrine glands. St Louis: C V Mosby, 1971:23-9.

6 Wegenke JD, Uehling DT, Wear JB Jr, et al. Familial Kallman's syndrome with unilateral renal aplasia. Clin Genet 1975;7: 268-81.

7 Ehrhardt P. Central diabetes insipidus with congenital cerebral anomaly. Br J Hosp Med 1989;41:380-1. 